\title{
Towards a Smart Manufacturing Toolkit for SMEs
}

\author{
Sameer Mittal ${ }^{1}$, David Romero ${ }^{2}$, Thorsten Wuest ${ }^{1}$ (corr. author) \\ ${ }^{1}$ Industrial and Management Systems Engineering, Benjamin M. Statler College of \\ Engineering and Mineral Resources, West Virginia University, Morgantown, WV, USA \\ samittal@mix.wvu.edu, thwuest@mail.wvu.edu \\ ${ }^{2}$ Tecnológico de Monterrey, Mexico \\ david.romero.diaz@gmail.com
}

\begin{abstract}
Technology, human and financial capitals will always be a significant constraint for manufacturing Small and Medium-sized Enterprises (SMEs). Keeping that in mind, this paper introduces a modular Smart Manufacturing (SM) Toolkit for SMEs as a set of technologies, methods, tools, and practices that can help manufacturing enterprises to increase their SM capabilities. The modular SM toolkit is composed of seven individual specialized toolboxes, which cover both technical and business management aspects of a successful digital transformation in a manufacturing SME. In addition, the various SME functions that can be supported with each individual toolbox are presented as well. The paper concludes with two short demonstration case studies as a means of an early validation mechanism for the SM toolkit in refinement.
\end{abstract}

Keywords: Digitalization, SMEs, Industry 4.0, Smart Manufacturing, Intelligent Manufacturing, Toolboxes, Toolkit.

\section{Introduction}

The goal of a Smart Manufacturing (SM) initiative is to optimize a production system with the help of a set of digital practices, technologies and other enabling factors that support the operations of a manufacturing enterprise [1] [2]. The discretion of practices, technologies and enabling factors that may be deployed by a manufacturing enterprise will depend on the degree of digitalization of its industrial sector (i.e., push-adoption) and/or self-conviction in pursuit of a new (digital) competitive advantage (i.e., pulladoption). In this sense, it is important to emphasize that developing an SM system represents both a technological and managerial challenge [3]. Therefore, shifting towards an SM practice should be both profitable and sustainable for a manufacturing enterprise. Although, the scientific literature has suggested a number of assessments, frameworks, maturity models and roadmaps for supporting the digital transformation of manufacturing enterprises towards the development of SM capabilities, the body of knowledge is lacking methods, tools and support systems for Small and Medium-sized Enterprises (SMEs).

According to Esmaelian, et al. [4]: "Manufacturing is continuously evolving from concept development to methods and tools available for the production of goods for use or sale. Traditionally, manufacturing refers to an industrial production process through which raw materials are transformed into finished products to be sold in the market. However, these days manufacturing is considered to be an integrated concept at all levels from machines to production systems to an entire business level operation". 
The evolution in the definition of "manufacturing" [4] has led to the establishment of new requirements for the development of manufacturing toolkits as a set of methods, tools, and practices. Different manufacturing initiatives, such as lean manufacturing [5] and digital manufacturing [6] have developed their own toolkits over the years that may help manufacturing enterprises in their shift towards more efficient production operations. These toolkits include a diverse range of items from cutting-edge CAx technologies, working tools, managerial principles, training methods, organizational practices, etc. However, when it comes to the recent SM initiative [1] [2], there is a void, or at least a very limited number, of toolkits aimed at supporting manufacturing enterprises (i.e., SMEs), in adopting the new 'smart' ways of production operations. Therefore, there is a need for systematizing the currently available SM methods, tools and practices in a modular toolkit providing a step-by-step and building-block approach for SMEs to develop SM capabilities in their own individual manufacturing systems.

This paper discusses the importance of SM toolkits for SMEs in the context of the Fourth Industrial Revolution or Industry 4.0. Section 2 focuses on available toolkits in the scientific body of knowledge. Section 3 proposes a modular SM toolkit that aims to help SMEs to develop SM capabilities. Following, two case studies validating the proposed toolkit are discussed in Section 4. Section 5 presents conclusions and further research work.

\section{Literature Review}

Toolkits may be considered as the set of organized working methods, physical and software tools, and managerial practices [7]. Every toolkit has its own objective. When it comes to manufacturing, there are a few toolkits available that may be considered as precursors for the development of an SM toolkit.

[5] categorized different lean tools and methods under five families to develop a modular toolkit: (a) JIT (pull-system, takt-time and Kanban systems), (b) TPM (OEE, SMED and 5S), (c) Automation (poka-yoke, andon and full work systems), (d) VSM (current state map, future state map and flow diagrams), and (e) Kaizen (brainstorming, continuous flow, five whys, Pareto-chart and Gantt-chart). The selection of the best lean toolkits for manufacturing SMEs has also been discussed in the literature [8], emphasizing the toolkits specific SME characteristics.

A target toolset, or toolkit, for digital manufacturing has been suggested by [6], considering five families: (a) manufacturing design and production simulation tools focus on value addition and waste reduction - e.g.: manufacturing planning, layout planning, process simulation and lean manufacturing, (b) production automation tools, e.g.: CNC machining, remote monitoring, PLC programming, machine vision, RFID and barcode technology, (c) robotic tools - which can be an alternative for human labour with a positive effect on production rate and quality, e.g.: office programming, material handling, welding and trimming, (d) additive manufacturing tools - for cost-reduction - e.g.: pre-moulding, prototyping and 3D-printing, and (e) digital scanning and measuring (metrology) - for economical design and process innovation, e.g.: 3D-laser scanning, reverse engineering and quality assurance.

[9] mentioned the following tools, or toolkit, for e-manufacturing: (a) predictive intelligence (e.g.: agents, algorithms, software), (b) scalable platform, (c) information compatibility between devices and business, (d) data-to-information-to-knowledge 
transformation tools, (e) synchronization systems for dynamic decision-making (e.g., CRM, SCM, B2B e-commerce systems), (f) tether-free communication systems, (g) employee education and training, and (h) flexible enterprise culture.

Similarly, a toolset or toolkit for small-scale intelligent manufacturing systems has been proposed by [3], where three broad categories were defined: (a) ICT as the use of information and communication technology for production management, e.g.: agent technology, cloud computing, mobile technology and remote monitoring, (b) artificial intelligence (AI) techniques in manufacturing as well as technologies like CAD, CNC machines, robots and virtual reality, and (c) others technologies like rapid prototyping, 3D measurements \& inspection, reverse engineering and reconfigurable machine tools.

An Industry 4.0 toolbox has been proposed by [10], for both product and process levels, including six distinct toolboxes each. At the product level: (a) sensor and actuator integration, (b) communication/connectivity, (c) functionality of data storage and information exchange, (d) monitoring, (e) product related IT services, and (f) business models. Similarly, at the process level: (a) data processing, (b) Machine-toMachine (M2M) communication, (c) company-wide networking with production, (d) ICT-infrastructure, (e) man-machine interfaces (HMIs), and (f) efficiency with small batches.

ICT has been considered as a fundamental technology in the aforementioned toolkits [3, 5, 6 and 8], but an operationalization perspective has been only offered by the Industry 4.0 toolbox [10]. The need of ICT, data and other application technologies such as CAD, CAM and recently 3D-printing, are the other vital factors that can be observed. Business models, charts, brainstorming, employee education, training, and skills enhancement programs are other organizational practices that were contemplated. Therefore, the available scientific literature presents several (general) toolboxes from both a technical and a managerial perspective. However, based on the literature review conducted in SCOPUS and Web of Science databases, there are a limited number of SM toolkits. Although there is an Industry 4.0 toolkit [10] available, this covers only the technical perspective (i.e., product and process families) and neglects the managerial view (i.e., employees' skills enhancement and business model aspects).

Due to the imminent pressure by OEMs to digitalize their whole value chains, SMEs need more than ever support in their digital transformation. A possible way to effectively support SMEs is by providing them with a modular SM toolkit, which can help them to follow a step-by-step and building-block approach for the needed actions to adopt SM technologies and business practices, and deliver both short-term and long-term results to themselves and their value chains. The short-term benefits/results should motivate SMEs to lower the entry barrier and start their digitalization journey towards new SM capabilities, whereas the long-term benefits should bring new competitive advantages to the manufacturing enterprise.

\section{Towards a Smart Manufacturing Toolkit for SMEs}

[6] proposed a Digital Manufacturing (DM) toolkit for SMEs. DM allows SMEs to virtually prototype and test multiple products and process designs; thus reducing design risks and ultimately costs. Whereas, $S M$ will allow/enable SMEs to connect all their manufacturing resources with each other and with their products in order to optimize 
their operations. Therefore, there is a need to provide a specific SM toolkit for manufacturing SMEs, which is currently not available in literature.

Table 1 presents a set of toolboxes that integrate and conform the proposed modular SM toolkit for SMEs. The proposed SM toolkit has been developed with the help of a literature review, discussions with experts from academia based in India, Mexico, and the United States, and further refined with the help of SME managers. As a result, some of the toolboxes, which were already partially available in the literature, were refined. Others, not available yet, were developed as part of this research work. Table 1 presents a list of toolboxes and their corresponding features, various technologies, methods, tools and practices that are considered under the proposed SM toolkit and the enterprise functions that the toolboxes serve (see also Tables 2 to 9).

Table 1: SM Toolkit: Features, Examples and Corresponding SME Functions

\begin{tabular}{|c|c|c|c|}
\hline Toolboxes & Features & Examples & SME Functions \\
\hline $\begin{array}{l}\text { Manufacturing/ } \\
\text { Fabrication } \\
\text { Tools } \\
\end{array}$ & $\begin{array}{l}\text { - Used for } \\
\text { manufacturing. } \\
\text { - Human involved }\end{array}$ & $\begin{array}{l}\text { - Lathe, Casting, } \\
\text { Carpentry, Mill, } \\
\text { Welding, etc. }\end{array}$ & - Manufacturing/Production \\
\hline $\begin{array}{l}\text { Design and } \\
\text { Simulation } \\
\text { Tools } \\
\text { [3] [6] } \\
\end{array}$ & $\begin{array}{l}\text { Deployed during } \\
\text { design phase \& } \\
\text { simulating } \\
\text { production }\end{array}$ & $\begin{array}{l}\text { - Process Simulation, } \\
\text { CAD, G-codes, } \\
\text { 3D-printing, etc. }\end{array}$ & $\begin{array}{l}\text { - Product Design } \\
\text { - Process Planning } \\
\text { - Operation(s) Times Estimation } \\
\text { - Manufacturing/Production }\end{array}$ \\
\hline $\begin{array}{l}\text { Robotics and } \\
\text { Automation } \\
\text { Tools } \\
{[6]}\end{array}$ & $\begin{array}{l}\text { Tools that can } \\
\text { perform } \\
\text { repetitive work. } \\
\text { - Automated and } \\
\text { modular } \\
\end{array}$ & $\begin{array}{l}\text { - Material Handling, } \\
\text { Conveyor Belts, } \\
\text { AS/RS, etc. } \\
\text { - Scanners/Printers, } \\
\text { etc. }\end{array}$ & $\begin{array}{l}\text { - } \text { Part/Product/Transportation/ } \\
\text { - Storage } \\
\text { - } \text { Quality Control and Inspection } \\
\text { - Reverse Engineering } \\
\text { - } \text { Manufacturing/Production }\end{array}$ \\
\hline $\begin{array}{c}\text { Sensors and } \\
\text { Connectivity } \\
\text { Tools } \\
\text { [3] [9] }\end{array}$ & $\begin{array}{l}\text { - Convert outputs } \\
\text { to readable } \\
\text { formats. } \\
\text { - Support } \\
\text { communication. }\end{array}$ & $\begin{array}{l}\text { Microcontrollers, } \\
\text { Boards, Sensors, } \\
\text { Actuators, Wi-Fi, } \\
\text { M2M, Digital } \\
\text { Readouts, Mobile } \\
\text { Apps, etc. }\end{array}$ & $\begin{array}{l}\text { - Quality Control } \\
\text { - Repair and Maintenance } \\
\text { - IT } \\
\text { - Dispatching } \\
\text { - Safety }\end{array}$ \\
\hline $\begin{array}{c}\text { Cloud/Storage } \\
\text { Tools }\end{array}$ & $\begin{array}{l}\text { - Provide space } \\
\text { for data storage. } \\
\text { - Stored data is } \\
\text { shareable by } \\
\text { host. }\end{array}$ & $\begin{array}{l}\text { Google Drive, } \\
\text { Microsoft } \\
\text { OneDrive, MS } \\
\text { Azure etc. } \\
\text { - External Hard-/ } \\
\text { Optical-Drives, etc. }\end{array}$ & $\begin{array}{l}\text { - IT } \\
\text { - Supply Chain Management } \\
\text { - Storing Investments, } \\
\text { Expenses, Sales, Payrolls, Tax } \\
\text { and Compliance, etc. }\end{array}$ \\
\hline $\begin{array}{c}\text { Data Analytics } \\
\text { Tools }\end{array}$ & $\begin{array}{l}\text { - Support data } \\
\text { analytics. }\end{array}$ & $\begin{array}{l}\text { Data Analytics, AI, } \\
\text { Optimization, } \\
\text { Statistics, Machine } \\
\text { Vision, etc. }\end{array}$ & $\begin{array}{l}\text { - Decision Making } \\
\text { - Purchasing \& Sales } \\
\text { - Evaluation Methods/Products/ } \\
\text { - Process/Employees } \\
\text { - Production Planning } \\
\text { - Statistical Quality Control } \\
\text { - Data Management } \\
\text { - Product Development } \\
\end{array}$ \\
\hline $\begin{array}{c}\text { Business } \\
\text { Management } \\
\text { Tools/Principles } \\
\text { [3] [8] }\end{array}$ & $\begin{array}{l}\text { Support } \\
\text { development of } \\
\text { business models, } \\
\text { awareness and } \\
\text { organizational } \\
\text { culture. }\end{array}$ & $\begin{array}{l}\text { - Collaboration, } \\
\text { - Attending } \\
\text { workshops, } \\
\text { - Reading reports, } \\
\text { Lean Practices, etc. }\end{array}$ & $\begin{array}{l}\text { - Employee Relations } \\
\text { - Employee Development } \\
\text { - Realizing organizational short- } \\
\text { term and long-term goals } \\
\text { - Change Management } \\
\text { Strategies } \\
\text { - Strategic Planning } \\
\text { - Deploying Standards } \\
\end{array}$ \\
\hline
\end{tabular}


A modular SM toolkit for SMEs must be a stepwise and building-block instrument, always considering a continuous improvement process and various maturity levels towards developing new SM capabilities. The proposed levels are: (a) novice, when a manufacturing SME is not aware of the benefits of adopting SM technologies, (b) beginner, when an SME is informed about the benefits of adopting SM technologies and has taken the first step towards the adoption of one or more SM technologies, (c) learner, when an SME has already started its 'digitalization journey' towards SM practices, (d) intermediate, when an SME has spent sufficient time, effort and resources in practicing the SM paradigm and has develop new SM capabilities, and (e) expert, when an SME has realized new competitive advantages through its SM capabilities.

Tables 2 to 9 present seven toolboxes as key components of the modular SM toolkit for SMEs composed by various technologies, methods, tools, and practices (from Table 1), which act as enablers for the progress of a manufacturing SME through the different maturity levels to achieve new, value-adding SM capabilities. Some toolboxes may require inputs from other toolboxes for their functioning. Therefore, in Tables' column three, those inputs of other toolboxes are specified.

Toolbox 1 - Fabrication/Manufacturing Tools (FMTs): This toolbox involves production processes where humans are directly involved in the operation of different machinery tools. It might even be considered as the traditional form of manufacturing. This research work assumes the presence of manufacturing machine tools such as lathe, mill, etc. at the SME. Table 2 shows the evolution of manufacturing systems based on the inputs (enablers) required to move forward to the next SM maturity level [11] [12] when developing SM manufacturing/fabrication capabilities. [11] and [12] consider the following inputs as enablers to develop new SM capabilities in a manufacturing/ fabrication system (see Table 2). The novice level requires working dextrously with raw materials that require only hand-tools for their transformation into products, whereas at the beginner level, power-tools such pneumatic and/or electric energy machines are now needed to work more efficiently with (new) raw materials. At the learner level, numerical control machines take the stage at the shopfloor for enabling larger production volumes (of parts/products), and for the later introduction of the first manufacturing information systems (e.g. CAD in Toolbox 2) \& MES) at the intermediate level. As both learner and intermediate stage need to mention the number of parts and products, the data analytics (see Toolbox 6) may be used as well. Finally, at the expert level, an SME starts to be concerned with the sustainability of its production resources, once it has managed to effectively achieving its production objectives.

Table 2: Fabrication/Manufacturing Toolbox (FMTs) and Maturity Levels

\begin{tabular}{|c|c|c|}
\hline Inputs Required & Levels & Toolbox \\
\hline Raw Materials & Novice & FMTs \\
\hline Energy & Beginner & FMTs \\
\hline Parts & Learner & FMTs, DATs \\
\hline Orders & Intermediate & FMTs, DATs, DSTs \\
\hline Sustainable Resources & Expert & FMTs \\
\hline
\end{tabular}

Toolbox 2 - Design and Simulation Tools (DSTs): This toolbox considers the use of simulations of how actual production process should work. It involves the digital imitation of the manufacturing process environment. DST might be used during the 
design and ramp-up phase of a production line (see Table 3). The design and simulation process begins with paper-based designs, next level is when a design environment and model are present, a more sophisticated level involves software that can actually simulate how a product/part will behave in real-world, subsequently prototypes deploying 3D-printing (see Toolbox 3) may be produced using the design in the next level, and finally an interface is available for both producers and customers to actually interact with the product/part.

Table 3: Design and Simulation Toolbox (DSTs) and Maturity Levels

\begin{tabular}{|c|c|c|}
\hline Inputs Required & Levels & Toolbox \\
\hline Paper-based design & Novice & CSTs \\
\hline $\begin{array}{c}\text { Environment \& Model } \\
\text { (Design Environment) }\end{array}$ & Beginner & DSTs \\
\hline Simulation Software & Learner & DSTs \\
\hline 3D Prototypes & Intermediate & RATs \\
\hline Interface (Configurators) & Expert & SCTs \\
\hline
\end{tabular}

Toolbox 3 - Robotics and Automation Tools (RATs): This toolbox will support the elimination of strenuous and repetitive work by means of automation. Robots and other automation tools will be able to perform repetitive tasks more efficiently as compared to humans. Robots and other automation solutions will need to be installed as part of the manufacturing systems. RATs are the first step towards production automation. Since RATs need a separate investment, SMEs may consider purchasing them on the basis of their critical operations. Therefore, they can be classified in different levels that may require new hardware acquisitions during the SM maturity journey (see Table 4). The novice level of this toolbox requires manually-operated machines, whereas the beginner level involves non-programmable machines, which can be controlled by changing their basic parameters like speed, direction, etc. Moreover, at the learner level, programmable machines are introduced, while at the intermediate level, collaborative robots mimic human-motions and learn with experience. Finally, at expert level, the collaborative robots operate by deploying AI. Different families of RATs based on their functions have also been considered (see Table 5).

Table 4: Robotics and Automation Tools (RATs) and Maturity Levels

\begin{tabular}{|c|c|c|}
\hline Inputs Required & Levels & Toolbox \\
\hline Manually-Operated Machines & Novice & RATs \\
\hline Non-Programmable Machines & Beginner & RATs \\
\hline Programmable Machines & Learner & RATs \\
\hline Collaborative Robot (mimic human) & Intermediate & RATs \\
\hline Collaborative Robot (based on AI) & Expert & RATs \\
\hline
\end{tabular}

Table 5: Robotics and Automation Tools Families and Functions (RATs)

\begin{tabular}{|c|l|}
\hline Family & \multicolumn{1}{c|}{ Function } \\
\hline Quality \& Inspection & They are used for maintaining quality in the manufacturing systems. \\
\hline Pick-n-Place & They are used for inter- and intra-departmental transportation. \\
\hline
\end{tabular}

Toolbox 4 - Sensors and Connectivity Tools (SCTs): This toolbox includes sensors that can convert manufacturing processes outputs into readable formats. Their installation in machine tools helps to measure the required data for a better production 
management. Thus, helping in networking and sharing the data/information needed for a smart production planning and control [13]. The first level of this toolbox requires a source in the form of a physical body like raw materials (see FMT) or tools (see RBT), the second level requires sensors that can sit on the source, in the third level, the sensors will be able to convert the signals in readable formats, at the fourth level, the data can be stored, and finally at the expert level the user is able to operate with the help of an interface (see Table 6).

Table 6: Sensors and Connectivity Toolbox (SCTs) and Maturity Levels

\begin{tabular}{|c|c|c|}
\hline Inputs Required & Levels & Toolbox \\
\hline Source & Novice & FMTs, RBTs \\
\hline Sensors & Beginner & SCTs \\
\hline Signals and Converters & Learner & SCTs \\
\hline Storage & Intermediate & CSTs \\
\hline Interface & Expert & SCTs \\
\hline
\end{tabular}

Toolbox 5 - Cloud/Storage Tools (CSTs): This toolbox enables to store and share data. Nowadays, there is an abundance of online/cloud platforms that provide various facilities for data storage and sharing. For SMEs, the CST toolbox (see Table 7) begins with registering data by manually entering it in paper-based logbooks or spreadsheets to store data, in the second level, data storage is made in built-in hard drives (HDs), whereas in the third level, data store is made in shared HDs (i.e., flash drives, intranet, etc.), finally as data increases, massive data storage may be required based on cloud and/or fog solutions corresponding to the fourth and fifth maturity levels respectively. The difference between these two levels is minor as both fog and cloud have similar resources and services. But fog is able to reduce network congestion and latency [14].

Table 7: Cloud/Storage Toolbox (CSTs) and Maturity Levels

\begin{tabular}{|c|c|c|}
\hline Inputs Required & Levels & Toolbox \\
\hline $\begin{array}{c}\text { Registers, Logbooks, } \\
\text { Spreadsheets }\end{array}$ & Novice & CSTs \\
\hline Built-in HDs & Beginner & CSTs \\
\hline Shared HDs & Learner & CSTs \\
\hline Cloud & Intermediate & CSTs \\
\hline Fog & Expert & CSTs \\
\hline
\end{tabular}

Toolbox 6 - Data Analytics Tools (DATs): This toolbox contains methods for data analytics. It includes a large family of statistical methods, optimization techniques, heuristics, etc. There are five main levels of data analytics [15]. During the first level, data collection is done by the input sources mentioned in Table 7; in the beginner level, data is cleaned; in the learner level, the meaningful data from various sources is combined; at the next level, data is reduced with the help of various rules; and finally data is transformed or normalized to avoid, e.g., redundancies (Table 8).

Table 8: Data Analytics Toolbox and Maturity Levels (DATs) [15]

\begin{tabular}{|c|c|c|}
\hline Inputs Required (Processes) & Levels & Toolbox \\
\hline Data collection & Novice & CSTs \\
\hline Data cleaning & Beginner & DATs \\
\hline Data integration & Learner & DATs \\
\hline Data reduction & Intermediate & DATs \\
\hline Data transformation & Expert & DATs \\
\hline
\end{tabular}


Toolbox 7 - Business Management Tools (BMTs): This toolbox involves a lot more than technology. For example, it deals with practices that manufacturing SMEs need to develop and follow as part of a new SM culture. This toolkit considers managerial oriented aspects towards an SM culture such as employees' skills enhancement, lean culture, employee/employer shared mind-sets, positive organizational culture, keeping the organization updated about the latest trends in SM with the help of workshops, seminars and reading grey papers. Since this toolbox motivates the SME at all levels towards an SM culture and practice, therefore, this toolbox is one of the most essential and might be considered as a foundation for successfully developing SM capabilities. This toolbox considers also the five maturity levels defined for each of the business principles included, since the adoption of new business practices comes together with the adoption of the other technology-based SM toolboxes and vice versa. Selected BMT tools have been described in Table 9.

Table 9: Business Management Toolbox (BMTs) [Adapted from 16]

\begin{tabular}{|c|l|}
\hline Principle/Practices & \multicolumn{1}{c|}{ Description } \\
\hline Lean Thinking & Eliminating all forms of waste in a production process. \\
\hline Organizational Culture & System where employees share the same set of beliefs and values. \\
\hline Employee Involvement & $\begin{array}{l}\text { Activity where employees (not involved in R\&D) can share their } \\
\text { ideas, knowledge and play a role in organisation's decisions. }\end{array}$ \\
\hline Customer Involvement & Products are designed based on customer voice/feedbacks. \\
\hline Collaboration & Products are designed considering supplier feedbacks. \\
\hline
\end{tabular}

As observed from Tables 2 to 9, a combination of different tools from several toolboxes might be required before the stepwise deployment of a particular toolbox. Implementing IoT technology requires sensors and actuators to be installed, Wi-Fi connectivity, data storage, and data analysis. Therefore, it will need to integrate SCTs, CSTs and DATs toolboxes.

\section{Demonstration Case Studies}

In addition to introducing the toolboxes as a means of integrating the proposed modular SM toolkit, it is important to identify the issues faced by SMEs during their adoption as well as how the proposed toolboxes may be deployed. As a result, this paper presents two short cases studies, where we present a stepwise deployment of the SM toolkit.

Digital Read Outs in Lathes and Mills: Two seasoned analogue lathe and mill machines had been lacking the needed accuracy on the shop floor. Job accuracy was mainly dependent on the skill and the experience of their individual operators. Considering budget constraints, the SME owner installed digital readouts (DROs). The DROs deployment made possible to ensure that the actual displacement with reference point is shown on the screen and the operator was no longer expected to set the zero for DROs repeatedly. The DROs may be considered as a part of the SCTs toolbox. Since a screen was attached to the lathe and mill itself (see Fig. 1), therefore, the wireless connectivity was not required in this case. Table 10 presents the various levels for installing the DROs in lathe and mill machine tools and shows how the toolbox helped the lathe and mill to shift from a "novice" to a "learner" - in the SCT toolbox levels. 

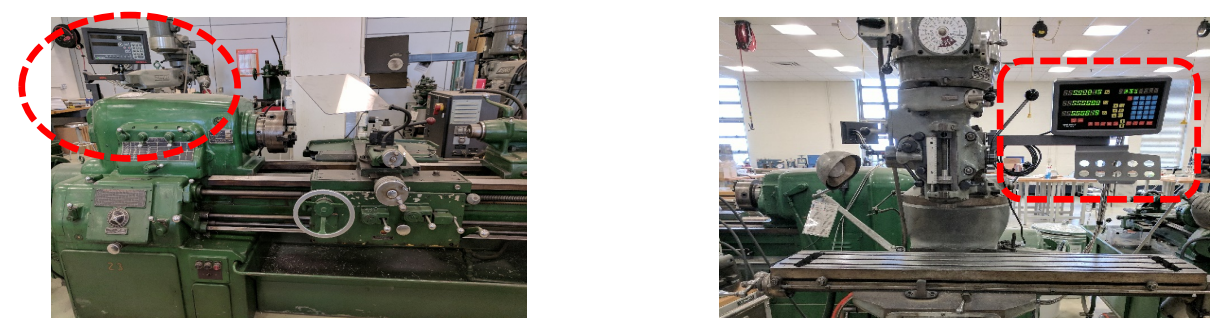

Figure 1. Smart Lathe (left) and Smart Mill (right) after DROs Installantion

Table 10: SCTs Toolbox for DRO Installation in Lathe and Mill Machine Tools

\begin{tabular}{|c|c|c|}
\hline Inputs Required & Levels Went Through & Toolboxes Required \\
\hline Lathe/Mill & Novice & FMTs \\
\hline DRO Sensors & Beginner & SCTs \\
\hline Signals, Converters & Learner & SCTs \\
\hline
\end{tabular}

Visual Inspection in Garment Industry: The SME was facing problems with manual inspections. The defects identification in the garment varied based on the subjective judgement of the worker the hour of the day. As a result, to improve the consistency in identifying defects and quality problems, an installation of a fabric inspection machine was suggested. For this improvement project, the RATs toolbox would be used and it will help the SME to make the cloth inspection more consistent. The fabric inspection machine will have a light box installed under the platform for inspecting the garment, also allowing the worker to adjust the speed of roll. Since the visual inspection machine will be operated by a human, therefore, it can be considered that the inspection process in the Garment industry shifted from a "novice" to a "beginner" (see Table 11). Additionally, if a digital fabric inspection machine is installed the fibre defects can be detected with the help of the sensors [17].

Table 11: RATs Toolbox for Visual Inspection Installation in Garment Industry

\begin{tabular}{|c|c|c|}
\hline Inputs Required & Levels Went Through & Toolboxes Required \\
\hline Manually-Operated Machines & Novice & RATs \\
\hline Non-Programmable Machines & Beginner & RATs \\
\hline
\end{tabular}

\section{Conclusions and Further Research}

This paper presents a modular SM toolkit for SMEs consisting of seven individual toolboxes. Six toolboxes are technical in nature (fabrication/manufacturing; design and simulation; robotics and automation; sensors and connectivity; cloud/storage; data analytics), while one is managerial-oriented (business management). Moreover, the robotics toolbox has been accompanied with a robotics tools' families and functions sub-toolbox.

The technically oriented toolboxes have been complemented by selected business management tools via the seventh business management toolbox (see Table 9). The reason for this seventh toolbox is that to deploy successfully the SM toolkit, a change in the SMEs mind-set is required as well as a change in their organizational culture and other management aspects. Therefore, the proposed SM toolkit includes both technical 
and business management toolboxes. The stepwise and building-block approach of the SM toolkit is matched with SME specific requirements for its easy adoption by SMEs.

Although, the application of selected toolboxes (i.e. [3], [5], [6], [8] and 10]) has been demonstrated in an industrial setting, their full evaluation is a long-term commitment. Hence, the full validation of the proposed modular SM toolkit for SMEs is part of our planned future work. Our future work will additionally include the deployment of all presented SM toolboxes in more SMEs and the development of a corresponding SM maturity model for SMEs $\left(\mathrm{SM}^{3} \mathrm{E}\right)$ creating a comprehensive support system for SMEs.

\section{References}

1. Kusiak, A.: Smart Manufacturing. Int'1. J. of Production Research, pp. 1-10 (2017)

2. Mittal, S., Khan, M.A., Romero, D., Wuest, T.: Smart Manufacturing: Characteristics, Technologies and Enabling Factors. Part B: Journal of Engineering Manufacture (2017)

3. Huang, T.: Development of Small-Scale Intelligent Manufacturing Systems (SIMS): A Case Study at Stella Polaris AS, Master Thesis, Artic University of Norway (2016)

4. Esmaeilian, B., Sara, B., Ben W.: The Evolution and Future of Manufacturing: A Review. Journal of Manufacturing Systems, 39: 79-100 (2016)

5. Belekoukias, I., Garza-Reyes, J.A., Kumar, V.: The Impact of Lean Methods and Tools on the Operational Performance of Manufacturing Organisations. Int'l. J. of Production Research, 52(18):5346-5366 (2014)

6. Kaartinen, H., Pieskä, S., Vähäsöyrinki, J.: Digital Manufacturing Toolbox for Supporting the Manufacturing SMEs. $7^{\text {th }}$ IEEE Int'1. C. Cognitive Infocommunications, 71-76 (2016)

7. Odedairo, B.O., Bell, D.: Framework for Introducing and Implementing Value Methods: A Novel Toolkit for Small \& Medium Scale Industries in Developing Nations. Int'1. J. of Basic \& Applied Sciences, 9(10):130-146 (2010)

8. Alaskari, O., Ahmad, M. M., Pinedo-Cuenca, R.: Development of a Methodology to Assist Manufacturing SMEs in the Selection of Appropriate Lean Tools. International Journal of Lean Six Sigma, 7(1):62-84 (2016)

9. Lee, J.: e-Manufacturing: Fundamental, Tools, and Transformation. Robotics \& ComputerIntegrated Manufacturing, 19(6):501-507 (2003)

10. Anderl, R., Picard, A., Wang, Y., Fleischer, J., Dosch, S., Klee, B. and Bauer, J.: Guideline Industrie 4.0: Guiding Principles for the Implementation of Industrie 4.0 in Small and Medium Sized Businesses. VDMA Forum Industrie, Vol. 4 (2015)

11. Cusumano, M.A.: Shifting Economies: From Craft Production to Flexible Systems and Software Factories. Research Policy, 21(5):453-480 (1992)

12. Bi, Z., Da Xu, L., Wang, C.: Internet of Things for Enterprise Systems of Modern Manufacturing. IEEE Transactions on Industrial Informatics, 10(2):1537-1546 (2014)

13. Nelles, J., Kuz, S., Mertens, A., and Schlick, C. M.: Human-Centered Design of Assistance Systems for Production Planning and Control: The Role of the Human in Industry 4.0. In Industrial Technology (ICIT), IEEE Int'1. Conference: 2099-2104 (2016)

14. Osanaiye, O., et al.: From Cloud to Fog Computing: A Review and a Conceptual Live VM Migration Framework. IEEE Access, 5: 8284-8300 (2017)

15. Han, J., Pei, J., Kamber, M.: Data Mining: Concepts and Techniques. Elsevier (2011)

16. Vrande, V., De Jong, J., Vanhaverbeke, W., De Rochemont, M.: Open Innovation in SMEs: Trends, Motives and Management Challenges. Technovation, 29(6-7):423-437 (2009)

17. Li, Y., Ai, J. and Sun, C.: Online Fabric Defect Inspection using Smart Visual Sensors. Sensors, 13(4):4659-4673 (2013) 